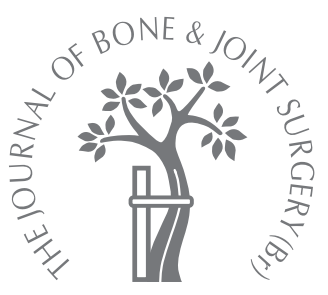

N. Thompson, J. Stebbins, M. Seniorou, A. M. Wainwright, D. J. Newham, T. N. Theologis

From the Nuffield Orthopaedic Centre, Oxford, United Kingdom

N. Thompson, MSc, MCSP, Clinical Specialist in Gait Analysis

I. J. Stebbins, DPhil, SRCS,

Clinical Scientist

M. Seniorou, DPhil,

Researcher

A. M. Wainwright, BSc, FRCS,

Consultant Orthopaedic

Surgeon

T. N. Theologis, MSc, PhD,

FRCS, Consultant Orthopaedic

Surgeon

Oxford Gait Laboratory

Nuffield Orthopaedic Centre,

Headington, Oxford OX3 7LD,

UK.

D. J. Newham, PhD, FCSP,

Professor of Physiotherapy and Director of Applied Biomedical

Research

Division of Applied Biomedical Research,

King's College, Strand, London, WC2R 2LS, UK.

Correspondence should be sent to Mrs N. Thompson; e-mail: nicky.thompson@noc.nhs.uk

(c)2010 British Editorial Society of Bone and Joint Surgery doi:10.1302/0301-620X.92B10. $24307 \$ 2.00$

$J$ Bone Joint Surg $[\mathrm{Br}]$ 2010;92-B:1442-8.

Received 23 December 2009;

Accepted after revision 18 May 2010

\title{
The use of minimally invasive techniques in multi-level surgery for children with cerebral palsy
}

\author{
PRELIMINARY RESULTS
}

This study compares the initial outcomes of minimally invasive techniques for single-event multi-level surgery with conventional single-event multi-level surgery. The minimally invasive techniques included derotation osteotomies using closed corticotomy and fixation with titanium elastic nails and percutaneous lengthening of muscles where possible. A prospective cohort study of two matched groups was undertaken. Ten children with diplegic cerebral palsy with a mean age of ten years six months (7.11 to 13.9) had multi-level minimally invasive surgery and were matched for ambulatory level and compared with ten children with a mean age of 11 years four months (7.9 to 14.4) who had conventional singleevent multi-level surgery. Gait kinematics, the Gillette Gait Index, isometric muscle strength and gross motor function were assessed before and 12 months after operation.

The minimally invasive group had significantly reduced operation time and blood loss with a significantly improved time to mobilisation. There were no complications intraoperatively or during hospitalisation in either group. There was significant improvement in gait kinematics and the Gillette Gait Index in both groups with no difference between them. There was a trend to improved muscle strength in the multi-level group. There was no significant difference in gross motor function between the groups.

We consider that minimally invasive single-event multi-level surgery can be achieved safely and effectively with significant advantages over conventional techniques in children with diplegic cerebral palsy.

Single-event multi-level surgery is most commonly performed in ambulant children with spastic diplegic cerebral palsy (CP). It usually involves a combination of bony and soft-tissue procedures to correct complex lower-limb deformities, improve gait and reduce the child's exposure to repeated operations and rehabilitation. Although this surgery is valuable in the care of children with cerebral palsy, post-operative recovery of function is a long and difficult process.

Femoral and tibial derotation osteotomies are often part of conventional multi-level surgery. In the femur, although there is debate about the advantages and disadvantages of proximal (intertrochanteric) or distal (diaphyseal or supracondylar) osteotomy, ${ }^{1,2}$ the results of rotational osteotomy are effective and lasting. ${ }^{3}$ However, the procedure usually necessitates a period of post-operative immobilisation lasting from 4.5 to 7.6 weeks. ${ }^{1,2}$ Failure of the fixation following early weight-bearing is a potential problem, as well as nonunion, infection and incomplete correction. ${ }^{2,4}$ Open osteotomy involves extensive soft-tissue dissection and periosteal stripping, which may contribute to these complications. Postoperative pain and immobility resulting from extensive dissection of muscles further compromise pre-existing weakness.

Correction of lower-limb contractures in CP is achieved by muscle-tendon recession or fractional lengthenings. Since muscle-tendon lengthening procedures are known to reduce muscle strength ${ }^{5,6}$ the technique of lengthening at the musculotendinous junction is widely used to minimise loss of strength and accelerate recovery. However, in contrast to animal studies, where loss of strength following a muscletendon lengthening recovers completely within six weeks, ${ }^{6}$ there is limited evidence suggesting that recovery of muscle strength in CP following a single lengthening may take up to seven to nine months. ${ }^{7,8}$ Recovery from bony surgery will generally take much longer. The combination of bony and soft-tissue multi-level surgery is associated with slow, prolonged and intensive rehabilitation. ${ }^{9,10}$ Seniorou et $\mathrm{al}^{11}$ recently showed that despite significant improvements in gait one year after multi-level surgery, muscle 
Table I. Details of gender, age, weight, Gross Motor Function Classification System level and surgical procedures for all subjects

\begin{tabular}{|c|c|c|c|c|c|c|c|c|c|c|c|c|c|c|}
\hline Patient ${ }^{*}$ & Gender & $\begin{array}{l}\text { Age at } \\
\text { surgery } \\
(y / m)\end{array}$ & $\begin{array}{l}\text { Weight } \\
\text { (kg) }\end{array}$ & $\begin{array}{l}\text { GMFCS }^{\dagger} \\
\text { level }\end{array}$ & FDO $^{\ddagger}$ & TDO $^{\S}$ & CLO & Psoas & Add** & $\mathrm{Ham}^{\dagger t}$ & $\mathbf{R F}^{\ddagger \neq}$ & Gast $^{\S \S}$ & TPशा & Other \\
\hline \multicolumn{15}{|c|}{ MI-SEMLS } \\
\hline 1 & $\mathrm{M}$ & 9.4 & 24 & II & $\mathrm{R}^{* * *}$ & & $\mathrm{R}$ & & $\mathrm{R}$ & $\mathrm{R}$ & $\mathrm{R}$ & $\mathrm{R}$ & & \\
\hline 2 & $M$ & 13.9 & 49 & 1 & $\mathrm{~L}$ & L & $\mathrm{L}$ & & $\mathrm{L}$ & $\mathrm{L}$ & $\mathrm{L}$ & & & \\
\hline 3 & $\mathrm{M}$ & 11.6 & 32 & II & B & & & & $\mathrm{R}$ & B & B & B & & \\
\hline 4 & $\mathrm{M}$ & 9.7 & 45 & I & B & & B & & B & B & B & B & & \\
\hline 5 & $M$ & 7.11 & 24 & III & $B$ & & & & $B$ & $B$ & $B$ & $B$ & & \\
\hline 6 & $\mathrm{M}$ & 8.5 & 47 & III & B & & & & B & B & B & B & & \\
\hline 7 & $\mathrm{~F}$ & 11.6 & 47 & II & B & & B & & B & B & B & B & & \\
\hline 8 & $\mathrm{~F}$ & 12.2 & 51 & II & B & & & & B & B & & & & \\
\hline 9 & $\mathrm{M}$ & 11.7 & 37 & II & B & & B & & B & B & B & & & \\
\hline 10 & $\mathrm{M}$ & 10.8 & 35 & II & B & & & & $\mathrm{R}$ & B & B & B & $\mathrm{R}$ & \\
\hline \multicolumn{15}{|l|}{ SEMLS } \\
\hline 11 & $\mathrm{M}$ & 9.3 & 32 & II & B & & B & B & & B & B & B & & \\
\hline 12 & $\mathrm{~F}$ & 14.4 & 55 & 1 & B & & & & & B & & B & & \\
\hline 13 & $\mathrm{M}$ & 11.2 & 34 & II & $\mathrm{L}$ & & & B & & B & B & B & & \\
\hline 14 & $\mathrm{~F}$ & 10.3 & 28 & II & B & & & B & & B & B & B & & \\
\hline 15 & $\mathrm{~F}$ & 11.5 & 20 & III & B & & $\mathrm{L}$ & & $\mathrm{L}$ & B & & B & & \\
\hline 16 & $\mathrm{~F}$ & 12.9 & 32 & III & B & & & B & & $B$ & & B & $B$ & L Acetabuloplasty \\
\hline 17 & $\mathrm{M}$ & 11.6 & 52 & II & B & & $\mathrm{B}$ & & $\mathrm{B}$ & B & & B & & B Subtalar arthrodesis \\
\hline 18 & $\mathrm{M}$ & 13.11 & 47 & II & $\mathrm{R}$ & & & & & $\mathrm{R}$ & & $\mathrm{R}$ & & R Acetabuloplasty \\
\hline 19 & $\mathrm{~F}$ & 11.7 & 26 & II & B & & $\mathrm{B}$ & B & & B & B & B & & \\
\hline 20 & $\mathrm{~F}$ & 7.9 & 27 & II & $\mathrm{R}$ & & $\mathrm{L}$ & & & B & B & B & $\mathrm{R}$ & \\
\hline
\end{tabular}

strength remained significantly less than before operation, and gross motor function returned to pre-operative levels but was not improved by surgery.

In order to achieve the optimum benefit from multilevel surgery, surgical techniques and post-operative rehabilitation need to improve. We have combined new techniques with post-operative strength training to allow early mobilisation and preservation of muscle strength for children with CP. We describe the preliminary results of a pilot study comparing the outcomes of minimally invasive single-event multi-level surgery with conventional multilevel procedures.

\section{Patients and Methods}

Ten children with spastic diplegic CP with a mean age of 10.6 years (7.11 to 13.9$)$ had minimally invasive surgery on 18 limbs. They were matched for ambulatory levels I-III using the Gross Motor Functional Classification System

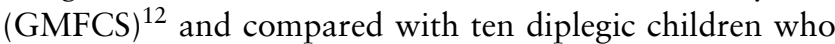
underwent conventional multi-level surgery on 20 limbs (mean age at surgery 11.4 years (7.9 to 14.4) (Table I)). Patients were excluded if they had been treated with botu- linum toxin or had undergone surgery to the lower limbs in the year before the multi-level procedures.

Both cohorts were recruited prospectively and were sequential. We first studied the multi-level group. Once the minimally invasive techniques were developed and approved for introduction into our unit, we utilised them on all spastic diplegic patients listed for multi-level surgery and continued to collect data prospectively. The first ten patients who underwent minimally-invasive surgery and followed for one year have been matched for gross motor function with ten out of a total cohort of 20 SEMLS patients.

All children in both groups underwent simultaneous bony and soft-tissue procedures by the same surgical team (TNT, AMW). The combination of procedures for each child was decided on pre-operative clinical examination and threedimensional (3D) gait analysis. In particular, the decision to perform derotation osteotomy was based on the measurement of femoral anteversion ${ }^{13}$ and rotation of the hip on the transverse plane kinematics. When both these measurements were abnormal, derotation osteotomy was recommended.

Standard surgical techniques were used in the conventional multi-level group. Open fractional lengthening at the 


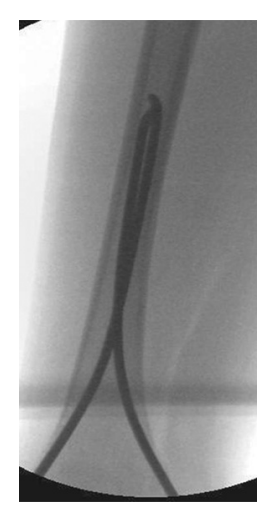

Fig. 1a

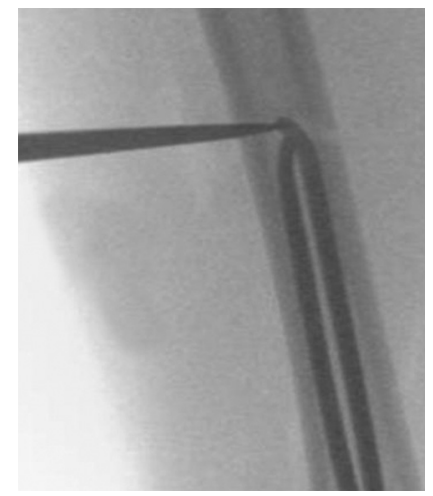

Fig. 1b

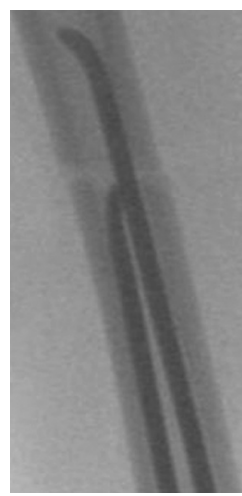

Fig. 1c

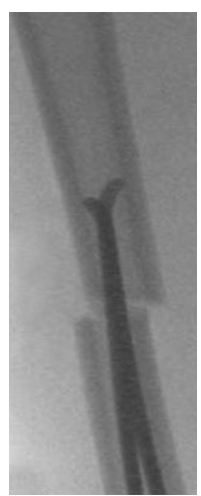

Fig. 1d

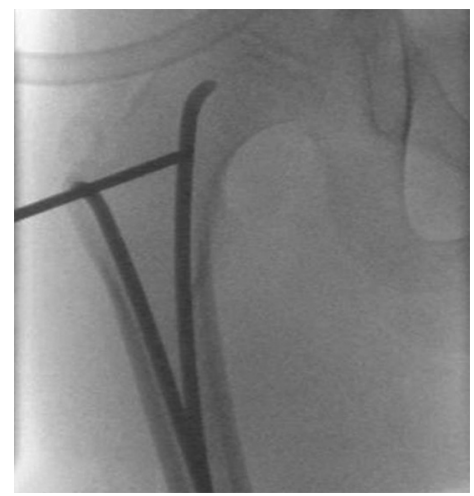

Fig. 1e

Anteroposterior intra-operative radiographs of the right femur during corticotomy and fixation with titanium elastic nails showing a) insertion of the nails, b) closed corticotomy using an osteotome, c) advancement of the nails, d) rotational correction and e) a view of the right hip with the nails advanced into the proximal femur and the reference wire used for anteversion.

musculotendinous junction was undertaken when indicated. Derotation femoral osteotomy was performed at the intertrochanteric level and fixed with an angled blade-plate or at the subtrochanteric level with a straight plate. Tibial osteotomy was carried out at the supramalleolar level and fixed with a plate. Transfer of the rectus femoris to sartorius or gracilis was also undertaken using an open technique. A calcaneal lengthening osteotomy was performed as described by Mosca. ${ }^{14}$

In the minimally invasive group, fractional lengthening of musculotendinous units was undertaken using percutaneous techniques. During these procedures, the assistant brought the muscle group to be addressed under stretch. For example, in the case of the hamstrings, the leg would be brought to the position of maximum measurement of the popliteal angle. In this position the surgeon would undertake multiple (usually between two and five) percutaneous transverse incisions ( $1 \mathrm{~mm}$ to $2 \mathrm{~mm}$ length) in the musculotendinous area until the position had improved to the desired level (e.g. a popliteal angle of $30^{\circ}$ or a plantigrade position of the ankle). In the case of gastrocnemius, a mini-open technique through a $2 \mathrm{~cm}$ incision was used to protect the sural nerve and divide the gastrocnemius aponeurosis, while preserving soleus. Transfer of the rectus to gracilis was undertaken using a mini-open technique. Calcaneal osteotomies were fixed with a small fragment AO plate (Synthes Inc., Davos, Switzerland) to achieve immediate stability.

An innovative technique was used for derotation osteotomy of the femur and tibia, based on closed corticotomy and fixation with the titanium elastic nails (Synthes Inc.). In the femur, a reference anteversion wire was inserted in a neutral position in the femoral neck. The nails were inserted distally and advanced proximally to the isthmus under fluoroscopic control (Fig. 1). At this level, a percutaneous corticotomy was carried out with a drill and osteotome. The nails were advanced across the corticotomy and rotational correction achieved using the anteversion wire inserted in the femoral neck and measuring its angle with the transcondylar axis at the knee with a goniometer. Following correction of anteversion to $10^{\circ}$ to $15^{\circ}$, the nails were advanced further to obtain fixation in the proximal femur. A similar technique was used for the tibia. The tibial nails were inserted antegrade and the fibula left intact.

The immediate post-operative regime for the first three days was identical for both groups, involving bed exercises and continuous epidural infusion followed by oral analgesics as required. Knee immobilisers (gaiters) were used in both groups for three to four days post-operatively and subsequently for up to six months at night. Below-knee casts were used for six weeks in children who underwent gastrocnemius lengthening and/or tibial and calcaneal osteotomies. In patients who had conventional multi-level surgery and longbone osteotomies with plate fixation, weight-bearing was delayed for up to six weeks depending on the intra-operative assessment of the stability of the fixation. The patients who underwent minimally invasive surgery and had long-bone osteotomies fixed with titanium elastic nails were mobilised from the third day. Both groups used bilateral anterior ground-reaction ankle-foot orthoses for a minimum of six months to aid extension of the knee in the stance phase.

In addition to intensive routine post-operative physiotherapy a strength training programme was started after three months in the minimally invasive group, compared with after six months in the conventional multi-level group. Both groups followed a standardised strengthening protocol three times weekly for six weeks exercising the hip flexors, extensors and abductors, and knee flexors and extensors bilaterally. ${ }^{11}$

Clinical examination, gait kinematics and temporal parameters, isometric muscle strength and motor function were assessed in all children pre-operatively and 12 months after surgery. Routine radiographs were taken at six and 12 weeks. The operation time, blood loss, time to mobilisation and any complications were recorded. 
Table II. Operative details for the two groups

\begin{tabular}{llll}
\hline & $\begin{array}{l}\text { SEMLS }^{*} \text { group } \\
\text { Mean (SD) }\end{array}$ & $\begin{array}{l}\text { MI-SEMLS } \\
\text { Mean (SD) }\end{array}$ & proup \\
\hline Operation time (mins) & $229(66)$ & $165(26)$ & 0.013 \\
Blood loss (ml) & $297(109)$ & $132(77)$ & 0.004 \\
Mobilisation (days) & $42(17)$ & $9(4)$ & $<0.001$ \\
\hline * SEMLS, single-event multi-level surgery & \\
† MI-SEMLS, minimally invasive single-event multi-level surgery
\end{tabular}

Instrumented 3D gait analysis was performed using a 12camera Vicon MX40 motion analysis system (Vicon, Oxford, United Kingdom) and a conventional marker set on the pelvis and lower limbs. ${ }^{15}$ Subjects walked barefoot, where possible, along a $10 \mathrm{~m}$ walkway at their self-selected speed. A minimum of six trials were captured and averaged, and three representative trials were processed using PlugIn-Gait modelling software (Vicon). Velocity, cadence and step length were calculated and normalised according to the method described by Hof. ${ }^{16}$

Isometric muscle strength was measured using a combination of fixed and hand-held dynamometry with a digital dynamometer (MIE Medical Research Ltd, Leeds, United Kingdom) in standardised testing positions. ${ }^{11}$ Five muscle groups were tested in each leg: the hip flexors, extensors and abductors, knee flexors, and knee extensors at $90^{\circ}$ and $30^{\circ}$ of flexion. The maximum force of three efforts for each muscle group was used in the data analysis and normalised to body mass $(\mathrm{Nm} / \mathrm{Kg})$.

Motor function was assessed as the Gross Motor Function Measure (GMFM88) $\operatorname{score}^{17}$ using the total percentage score for analysis.

The Gillette Gait Index ${ }^{18}$ was used to calculate the amount by which a subject's gait deviated from an average normal profile, the deviation being represented as a single number. Routine radiographs were taken at six and 12 weeks after surgery and used to assess union at the site of the osteotomy.

Statistical analysis. This was undertaken on 20 limbs in the conventional multi-level and 18 in the minimally invasive group. A paired Students $t$-test was used to assess pre- and post-operative differences within the groups. Differences between the groups were assessed using analysis of covariance. The level of significance was set at $\mathrm{p}<0.05$.

\section{Results}

The minimally invasive group had a significantly reduced operation time ( $p=0.013)$, less blood loss $(p=0.004)$ and improved time to mobilisation $(\mathrm{p}<0.001)$, compared with the conventional multi-level group (Table II). There were no complications intra-operatively or in hospital in either group. In the minimally invasive group, patient 2 developed a transient left trochanteric bursitis and patient 3 developed transient neuropathic pain in the right foot. In the conventional group, there was one failure of fixation requiring revision when patient 20 fell at home five weeks post- operatively. Otherwise all osteotomies in both groups united within 12 weeks.

Pre-operatively, there were no significant differences in gait kinematics between the groups except for significantly increased knee flexion during stance in the conventional multi-level group $(\mathrm{p}=0.03)$. Both groups had significantly improved knee flexion in stance post-operatively and similar significant improvements in sagittal and coronal plane gait parameters. Furthermore, the Gillette Gait Index was significantly improved in both groups $(\mathrm{p}<0.001)$. The results are summarised in Table III.

In the conventional group, muscle strength was reduced at 12 months compared with pre-operatively in all lowerlimb muscle groups, except for the hip abductors (Fig. 2). This was significant in the knee flexors $(\mathrm{p}<0.001)$. In the minimally invasive group there was a significant reduction of knee flexor strength $(\mathrm{p}<0.001)$ at 12 months compared with pre-operatively, but improved strength in the hip abductors and knee extensors at $90^{\circ}$ and $30^{\circ}$. This was significant in the latter muscle group $(\mathrm{p}=0.01)$. When comparing the groups, the minimally invasive group had significantly greater knee flexor strength compared to the conventional group at 12 months post-operatively $(\mathrm{p}=0.048)$.

Gross motor function, as measured by the total percentage GMFM, showed no significant change from pre- to post-operative levels either within or between the groups.

\section{Discussion}

Improvements in gait following multi-level surgery are well documented. ${ }^{9,10,19,20}$ and compare favourably with deterioration in gait in untreated diplegic children. ${ }^{21}$ In our study, kinematic parameters in the sagittal and coronal planes were shown to be similarly improved by conventional and minimally invasive multi-level surgery. Excessive internal rotation of the hip and foot progression angles were significantly improved by femoral derotation osteotomy with conventional blade-plate fixation or titanium elastic nailing.

The use of titanium elastic nails is well established in the treatment of certain long bone fractures. It is a safe, minimally invasive method, with few complications, avoids injury to the growth-plate, does not require post-operative casts and is associated with short hospital stays and early mobilisation. ${ }^{22}$ Biomechanical studies have shown that using titanium elastic nails for fixation of the femur has adequate 
Table III. Gait, strength and function mean values pre-operatively and 12 months post-operatively

\begin{tabular}{|c|c|c|c|c|c|}
\hline & \multirow{2}{*}{$\begin{array}{l}\text { Healthy ( }=20 \text { legs) } \\
\text { Mean } \\
\text { (SD) }\end{array}$} & \multicolumn{2}{|c|}{$\begin{array}{l}\text { MI-SEMLS group } \\
\text { ( } n=18 \text { operated limbs) }\end{array}$} & \multicolumn{2}{|c|}{$\begin{array}{l}\text { SEMLS group } \\
\text { ( } n=20 \text { operated limbs) }\end{array}$} \\
\hline & & $\begin{array}{l}\text { Pre-operative } \\
\text { (SD) }\end{array}$ & $\begin{array}{l}\text { Post-operative } \\
\text { (SD) }\end{array}$ & $\begin{array}{l}\text { Pre-operative } \\
\text { (SD) }\end{array}$ & $\begin{array}{l}\text { Post-operative } \\
\text { (SD) }\end{array}$ \\
\hline \multicolumn{6}{|l|}{ Gait Parameters } \\
\hline Mean anterior pelvic tilt $\left({ }^{\circ}\right)$ & $9.8(5.3)$ & $17.88(3.11)$ & $18.65(7.49)$ & $15.92(4.64)$ & $18.97(9.89)$ \\
\hline Mean pelvic obliquity $\left({ }^{\circ}\right)$ & $2.3(1.6)$ & $6.16(4.35)$ & $6.64(2.97)$ & $9.14(7.47)$ & $7.07(7.42)$ \\
\hline Mean pelvic rotation $\left({ }^{\circ}\right)$ & $5.2(4.4)$ & $15.81(10.73)$ & $8.24(7.43)^{\dagger}$ & $15.61(14.21)$ & $12.37(16.09)$ \\
\hline Maximum hip flexion swing $\left({ }^{\circ}\right)$ & $35.9(6.3)$ & $49.98(8.27)$ & $48.22(8.95)$ & $52.85(9.37)$ & $50.16(11.23)$ \\
\hline Maximum hip extension $\left({ }^{\circ}\right)$ & $-12.7(4.6)$ & $6.66(11.52)$ & $8.12(12.62)$ & $9.34(14.14)$ & $8.14(17.25)$ \\
\hline Mean internal hip rotation $\left({ }^{\circ}\right)$ & $-0.7(5.0)$ & $13.68(12.45)$ & $0.80(7.96)^{\ddagger}$ & $12.17(12.84)$ & $1.56(9.94)^{\ddagger}$ \\
\hline Maximum knee extensor stance $\left(^{\circ}\right)$ & $2.2(5.4)$ & $22.20(18.06)$ & $14.29(13.54)^{\dagger}$ & $35.22(22.92)$ & $21.47(17.02)^{\dagger}$ \\
\hline Knee flexion initial contact $\left(^{\circ}\right)$ & $5.9(4.8)$ & $40.58(11.90)$ & $24.04(12.43)^{\ddagger}$ & $46.42(17.71)$ & $31.88(13.18)^{\ddagger}$ \\
\hline Range knee flexion $\left({ }^{\circ}\right)$ & $60.0(5.0)$ & 36.69 (15.69) & $42.62(13.76)^{*}$ & $31.19(14.21)$ & $38.46(12.30)^{*}$ \\
\hline Maximum knee flexion swing $\left(^{\circ}\right)$ & $60.6(6.3)$ & $58.59(13.44)$ & $56.64(10.92)$ & $66.30(14.15)$ & $59.85(8.10)^{\dagger}$ \\
\hline Time maximum knee flexion swing (\% cycl & 71.1 & $82.46(4.91)$ & $77.56(4.22)^{\dagger}$ & $82.91(3.82)$ & $79.58(5.47)^{\dagger}$ \\
\hline Maximum dorsiflexion stance $\left({ }^{\circ}\right)$ & $14.8(3.6)$ & $1.23(17.66)$ & $14.57(8.30)^{\dagger}$ & $13.86(12.74)$ & $16.94(6.89)$ \\
\hline Maximum dorsiflexion swing $\left({ }^{\circ}\right)$ & $2.4(1.9)$ & $-8.71(13.40)$ & $5.01(7.69)^{\dagger}$ & $2.12(15.30)$ & $9.18(7.95)^{*}$ \\
\hline Mean internal foot progression stance $\left({ }^{\circ}\right)$ & $-4.2(5.1)$ & $13.89(18.36)$ & $-6.63(14.85)^{\ddagger}$ & $14.73(13.81)$ & $0.40(14.51)^{\ddagger}$ \\
\hline Velocity (\% normal) & & $0.34(0.09)$ & $0.31(0.08)$ & $0.28(0.11)$ & $0.31(0.12)$ \\
\hline Cadence (\% normal) & & $0.56(0.09)$ & $0.56(0.09)$ & $0.50 \quad(0.11)$ & $0.52(0.12)$ \\
\hline Step length (\% normal) & & $0.58(0.09)$ & $0.56(0.11)$ & $0.55 \quad(0.15)$ & $0.58(0.14)$ \\
\hline Gillette gait index & $24.4(22.4)$ & $421.97(216.81)$ & $185.71(115.38)^{\ddagger}$ & $391.1(206.21)$ & $228.08(175.65)^{\ddagger}$ \\
\hline Muscle strength ( $\mathrm{Nm} / \mathrm{Kg}$ ) & ( $n=30$ legs) & & & & \\
\hline Knee flexors & $1.26(0.25)$ & $0.86(0.30)$ & $0.63(0.40)^{\ddagger \S}$ & $0.90 \quad(0.21)$ & $0.47(0.22)^{\ddagger}$ \\
\hline Knee extensors $90^{\circ}$ & $1.82(0.37)$ & $1.27(0.44)$ & $1.29(0.60)$ & $1.36(0.54)$ & $1.15(0.55)$ \\
\hline Knee extensors $30^{\circ}$ & $1.27(0.17)$ & $0.33(0.16)$ & $0.43(0.22)^{*}$ & $0.63(0.53)$ & $0.47(0.27)$ \\
\hline Hip flexors & $1.05(0.19)$ & $0.58(0.21)$ & $0.54(0.31)$ & $0.43(0.20)$ & $0.38(0.21)$ \\
\hline Hip extensors & $2.68(0.51)$ & $2.12(0.61)$ & $2.00(0.50)$ & $2.00(0.58)$ & $1.79(0.37)$ \\
\hline Hip abductors & $1.050 .29)$ & $0.42(0.11)$ & $0.46(0.21)$ & $0.54(0.21)$ & $0.58(0.35)$ \\
\hline \multicolumn{6}{|l|}{ Motor function } \\
\hline (Total \% GMFMף score) & & $80.41(9.13)$ & $79.34(8.74)$ & $82.44(14.71)$ & $85.06(13.9)$ \\
\hline \multicolumn{6}{|c|}{ * indicates significant within-group difference $p \leq 0.05$} \\
\hline \multicolumn{6}{|c|}{$\dagger$ indicates significant within-group difference $p \leq 0.01$} \\
\hline \multicolumn{6}{|c|}{$¥$ indicates significant within-group difference $p \leq 0.001$} \\
\hline \multicolumn{6}{|c|}{$\S$ indicates significant between-group difference $p \leq 0.05$} \\
\hline I GMFM, Gross Motor Function Measure & & & & & \\
\hline
\end{tabular}

stability in all three planes, including rotational stability. ${ }^{23}$ There is one report of solid locked nail fixation of femoral osteotomies in skeletally mature adolescents with cerebral palsy by Ferri-de-Barros, Inan and Miller $^{24}$ but, to our knowledge, titanium elastic nails have not previously been used in this context. By combining minimally invasive multiple soft tissue and bony operations in children with spastic diplegic CP, we found immediate clinical advantages when compared with the conventional multi-level surgery. The operative and therefore the anaesthetic time was significantly reduced. There was significantly less blood loss, thereby reducing the risk of peri-operative anaemia and possible transfusion. Titanium elastic nailing allowed rapid mobilisation in the first post-operative week compared with plate fixation, which required delayed weight-bearing for up to six weeks. These advantages also benefit the resources needed for complex multi-level orthopaedic surgery.

In the conventional multi-level group two patients underwent $\mathrm{Dega}^{25}$ acetabuloplasty for acetabular dyspla- sia without subluxation, which might imply a slower rehabilitation period. However, the two subjects (16 and 18 in Table I) mobilised at 46 and 56 days respectively, and a further six subjects in this group mobilised at between 46 and 64 days. There were three patients in the minimally invasive group with acetabular dysplasia without subluxation. As part of our changing approach we decided not to perform acetabuloplasties as part of minimally invasive surgery. There would be the risk that these hips could subluxate and require additional treatment. However, we believe the advantages of early mobilisation and rehabilitation outweigh this risk.

Percutaneous lengthening at the musculotendinous junction has been used in children with other pathologies to maximise preservation of muscle strength and speed of mobilisation. ${ }^{26}$ Gordon et $\mathrm{al}^{27}$ concluded that percutaneous lengthening of the medial hamstrings was a useful option in ambulant children with CP undergoing a variety of concomitant operations. They reported significantly 
improved knee extension at initial contact, but there was no group with an open hamstring procedure for comparison. We have shown significantly improved knee extension at initial contact and significantly improved maximum knee extension in stance both in the conventional group with open medial hamstring lengthening, and the minimally invasive group who had percutaneous lengthenings.

There was a mild but non-significant trend toward increased anterior pelvic tilt in both groups postoperatively, with a slight increase in hip extension in the conventional group and a slight decrease in hip extension in the minimally invasive group. This difference is likely to be caused by the psoas rather than hamstrings. Our percutaneous hamstring lengthenings were more conservative than the open type and post-operative hamstring strength was almost twice as great in those lengthened percutaneously as in those lengthened by an open technique. However, we did not undertake psoas lengthening in the minimally invasive group as this would have required an open procedure. As the overall value of psoas lengthening remains controversial we felt it was justified not to include this procedure as part of minimally invasive surgery.

The matching of groups with $\mathrm{CP}$ is challenging because of the many parameters which can affect gait and function. We chose the GMFCS as it is a validated classification system which reflects the level of function of the individual patients rather than specific parameters of gait. Some differences between groups were to be expected, but the only significant difference in gait kinematics between the two groups before surgery was significantly increased knee flexion during stance in the conventional multi-level group. Although this is a limitation of the study, our indications for multi-level surgery did not change during it. No patient in the conventional group had undergone previous lengthening of the tendo Achillis which may have contributed to increased crouch. We believe that the difference in knee kinematics between the groups was a random effect of the imperfections of the matching procedure.

There was a general trend for improved muscle strength in the minimally invasive group (Fig. 2). Five of the six muscle groups remained weaker than pre-operatively in the conventional multi-level group, whereas three muscle groups had improved strength in the minimally invasive group and the remaining three lost less strength than the conventional group. The hamstrings showed the greatest loss of strength in both groups, despite a cautious technique to avoid over-lengthening. They remained $48 \%$ weaker after open lengthening, but only $27 \%$ weaker when lengthened percutaneously. The hamstrings appear to be the muscle group most vulnerable to persistant loss of strength after surgery. This is despite prolonged and extensive rehabilitation with an additional resistance strengthening programme to which other lower limb muscles responded well. ${ }^{11}$ All subjects had derotation femoral osteotomies and both groups had improved

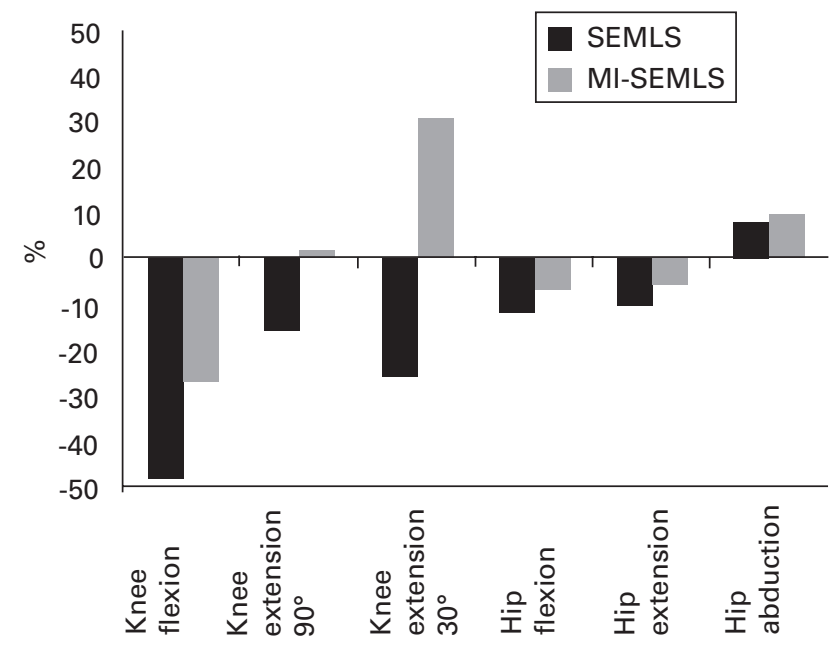

Fig. 2

Chart showing percentage change in muscle strength at 12 months postoperatively in the two groups (SEMLS, single-event multi-level surgery, MI-SEMS, minimally invasive single-event multi-level surgery).

strength in the hip abductors post-operatively. The correction of internal rotation corrects lever-arm dysfunction and therefore confers a biomechanical advantage on the hip abductors. ${ }^{13}$

Multi-level surgery in CP focuses on the correction of static and dynamic deformity with the aim of improving gait. It is, however, important that children who are straighter and more upright after correction of gait are not made weaker and less functional. Although an initial loss of motor function might be expected, the effect of bony and soft-tissue multi-level surgery on strength and function has not been evaluated specifically by others. Seniorou et $\mathrm{al}^{11}$ showed that motor function significantly deteriorated at six months after conventional multi-level surgery, but recovered by one year. In our study, motor function also returned to pre-operative levels one-year after surgery in both groups. Motor function peaks at about seven years of age in children with CP at GMFCS levels I to III. ${ }^{28,29}$ Thereafter, function remains stable at GMFCS levels I and II, but significantly declines at GMFCS level III. ${ }^{30}$ Therefore, restoration of function to pre-operative levels, rather than functional improvement, might be viewed as a realistic goal of rehabilitation and a positive outcome.

Our initial findings indicate that multi-level surgery can be achieved safely and effectively using minimally invasive techniques, with the additional benefits of improved muscle strength, faster mobilisation and reduced operative time and blood loss.

\section{Listen live}

Listen to the abstract of this article at www.jbjs.org.uk

The authors acknowledge the support of Joint Action Research.

No benefits in any form have been received or will be received from a commercial party related directly or indirectly to the subject of this article. 


\section{References}

1. Pirpiris M, Trivett A, Baker R, et al. Femoral derotation osteotomy in spastic diplegia: proximal or distal? J Bone Joint Surg [Br] 2003;85-B:265-72.

2. Kay RM, Rethlefsen SA, Hale JM, Skaggs DL, Tolo VT. Comparison of proximal and distal rotational femoral osteotomy in children with cerebral palsy. J Pediatr Orthop 2003;23:150-4.

3. Ounpuu S, DeLuca P, Davis R, Romness M. Long-term effects of femoral derotation osteotomies: an evaluation using three-dimensional gait analysis. $J$ Pediatr Orthop 2002;22:139-45.

4. Hau R, Dickens DR, Nattrass GR, et al. Which implant for proximal femoral osteotomy in children?: a comparison of the AO (ASIF) 90 degree fixed-angle blade plate and the Richards intermediate hip screw. J Pediatr Orthop 2000;20:336-43.

5. Moseley CF. Physiological effects of soft-tissue surgery. In: Sussman MB, ed. The diplegic child: evaluation and management. Rosemont: American Academy of Orthopaedic Surgeons, 1992:259-70.

6. Brunner R, Jaspers RT, Pel JJ, Huijing PA. Acute and long-term effects on muscle force after intramuscular aponeurotic lengthening. Clin Orthop 2000;378:264-73.

7. Reimers $\mathbf{J}$. Functional changes in the antagonists after lengthening the agonists in cerebral palsy: II. Quadriceps strength before and after distal hamstring lengthening. Clin Orthop 1990;253:35-7.

8. Damiano DL, Abel MF, Pannunzio M, Romano JP. Interrelationships of strength and gait before and after hamstrings lengthening. J Pediatr Orthop 1999;19:352-8.

9. Nene AV, Evans GA, Patrick JH. Simultaneous multiple operations for spastic diplegia: outcome and functional assessment of walking in 18 patients. J Bone Joint Surg [Br] 1993;75-B:488-94.

10. Gage JR, Fabian D, Hicks R, Tashman S. Pre- and post-operative gait analysis in patients with spastic diplegia: a preliminary report. J Pediatr Orthop 1984;4:715-25.

11. Seniorou M, Thompson $\mathbf{N}$, Harrington $\mathbf{M}$, Theologis $\mathbf{T}$. Recovery of muscle strength following multi-level orthopaedic surgery in diplegic cerebral palsy. Gait Posture 2007;26:475-81.

12. Wood E, Rosenbaum P. The gross motor function classification system for cerebral palsy: a study of reliability and stability over time. Dev Med Child Neuro/2000;42:292-6.

13. Ruwe PA, Gage JR, Ozonoff MB, DeLuca PA. Clinical determination of femoral anteversion: a comparison with established techniques. J Bone Joint Surg [Am] 1992;74-A:820-30

14. Mosca VS. Calcaneal lengthening for valgus deformity of the hindfoot: results in children who had severe, symptomatic flatfoot and skewfoot. J Bone Joint Surg [Am] 1995;77-A:500-12.

15. Davis R, Deluca P. Clinical gait analysis: current methods and future directions. In: Harris GF, Smith PA, eds. Human motion analysis: current applications and future directions. New York: Institute of Electrical and Electronic Engineers, 1996.
16. Hof AL. Scaling gait data to body size. Gait Posture 1996;4:222-3.

17. Russell DJ, Rosenbaum PL, Cadman DT, et al. The gross motor function measure: a means to evaluate the effects of physical therapy. Dev Med Child Neurol 1989;31:341-52.

18. Schutte LM, Narayanan U, Stout JL, et al. An index for quantifying deviations from normal gait. Gait Posture 2000;11:25-31.

19. Norlin R, Thaczuk H. One session surgery on the lower limb in children with cerebral palsy: a five year follow-up. Int Orthop 1992;16:291-3.

20. Saraph V, Zwick EB, Zwick G, et al. Multilevel surgery in spastic diplegia: evaluation by physical examination and gait analysis in 25 children. $J$ Pediatr Orthop 2002;22:150-7.

21. Gough M, Eve LC, Robinson RO, et al. Short-term outcome of multi-level surgical intervention in spastic cerebral palsy compared with the natural history. Dev Med Child Neurol 2004;46:91-7.

22. Barry M, Paterson JM. A flexible intramedullary nails for fractures in children. J Bone Joint Surg [Br] 2004;86-B:947-53.

23. Fricka KB, Mahar AT, Lee SS, Newton PO. Biomechanical analysis of antegrade and retrograde flexible intramedullary nail fixation of pediatric femoral fractures using a synthetic bone model. J Pediatr Orthop 2004;24:167-71.

24. Ferri-de-Barros F, Inan $\mathbf{M}$, Miller $\mathbf{F}$. Intramedullary nail fixation of femoral and tibial percutaneous rotational osteotomy in skeletally mature adolescents with cerebral palsy. J Pediatr Orthop 2006;26:115-18.

25. Mubarak SJ, Valencia FG, Wenger DR. One-stage correction of the spastic dislocated hip: use of pericapsular acetabuloplasty to improve coverage. J Bone Joint Surg [Am] 1992;74-A:1347-57.

26. Heckmatt JZ, Dubowitz V, Hyde SA, et al. Prolongation of walking in Duchenne muscular dystrophy with lightweight orthoses: review of 57 cases. Dev Med Child Neurol 1985;27:149-54.

27. Gordon AB, Baird GO, McMulkin ML, Caskey PM, Fergusen PL. Gait analysis outcomes of percutaneous medial hamstring tenotomies in children with cerebral palsy. J Pediatr Orthop 2008;28:324-9.

28. Rosenbaum PL, Walter SD, Hanna SE, et al. Prognosis for gross motor function in cerebral palsy: creation of motor development curves. JAMA 2002;288:1357-63.

29. Beckung E, Carlsson G, Carlsdotter S, Uvebrant P. The natural history of gross motor development in children with cerebral palsy aged 1 to 15 years. Dev Med Child Neurol 2007;49:751-6.

30. Hanna SE, Rosenbaum PL, Bartlett DJ, et al. Stability and decline in gross motor function among children with cerebral palsy aged 2 to 21 years. Dev Med Child Neurol 2009;51:295-302. 